\title{
Discourse and Development: Insights and Issues
}

\section{Introduction}

At the outset, we claimed that an understanding of Chinese economic discourse, its origins and evolution can provide valuable insight into the way China's political elite thinks about the economy, the objectives and mechanisms of governance, and, by extension, the ongoing transformation of the economic system. Those who study China's amalgam of market institutions and authoritarian administration have sought to capture its defining characteristics through a variety of terms, ranging from "Sino-capitalism" (McNally 2012 ) to the improbable oxymoron of "state neoliberalism" (Chu 2010). Notably, few outside observers have seen fit to define this system by its official appellate: the socialist market economy (shehui zhuyi shichang jingji). Yet, closer examination of this concept and its position within the greater system of central economic discourse reveals deeply entrenched motives and assumptions about the working of the economic system that would likely be glossed over by the Western perspectives discussed in the Introduction, which focus on the selfenforcing constraint of efficiency or the distribution of political power within an authoritarian system. One criticism we levelled against these approaches was that they are (implicitly) biased toward the post-Mao period of reforms and emphasize change over continuity. While the history of the concept of the socialist market economy spans just over two decades, the debates that shaped its defining features hark back to the early years of the establishment of the People's Republic. Within Chinese economic thought, the notions of accumulation, readjustment and reform in particular have been instrumental in shaping elite conceptualizations of economic development and governance. Although the scope and meaning of these concepts have been gradually redefined in response to the changing structure of the Chinese economy and its problems, they have been the red thread that runs through six decades of economic policy. As such, a thorough appreciation of Chinese economic discourse - which originated in the early years of the People's Republic — is indispensable to an understanding of the major changes and continuities in China's idiosyncratic economic system. 


\section{Readjustment and Reform: From Plan to Socialist Market Economy}

The notions of accumulation, readjustment and reform first appeared shortly after the adoption of the First Five Year Plan. In this formative period, the singular focus of Mao and his economic commandants was on the rapid establishment of a modern, industrialized economy. Economic discourse revolved around three major concerns. First was the matter of sectoral relations. Some economists and planners were adamant about the need for a balanced and proportionate trajectory of development given the low productivity of agriculture. However, Mao, inspired by the theories of Preobrazhensky and Fel'dman, insisted on a pattern of accelerated accumulation, whereby agricultural capital would be transferred to industry through an elaborate system of price manipulations. The mobilization and transfer of capital necessary to realize the expansive growth of industry required extensive central control over production and allocation. This technical requirement coincided with the ideological imperative to abolish private property, prompting the Party to rapidly proceed with the annexation of the means of reproduction. This pitted Mao against leaders in the economic bureaucracy (notably Chen Yun), who felt that an underdeveloped understanding of technical factors within the public economy had resulted in inefficient production processes, and who consequently argued for the partial reinstatement of market relations. Such proposals were anathema to Mao's interpretation of Marxism-Leninism, which held that the success in achieving rapid industrialization depended crucially on perfecting the socialist consciousness of the Chinese people. The strategy of readjustment (balanced and proportionate development) was formulated in 1956 in response to lagging productivity in the agricultural sector and comprised of two elements. First, accelerated accumulation was to be abandoned in favor of proportionate development of the sectors of the economy and, second, the overall investment rate was to be reduced so as to increase household consumption. Reform, that is, the partial reinstatement of market exchange and private property (initially in agriculture) was seen as a natural complement to readjustment because market production would incentivize idle rural labor while increasing discretionary income. Readjustment, which was widely implemented in the wake of the Great Leap Forward, also involved a more rigorous planning process. However, readjustment policies were vehemently opposed by Mao, who in 1966 launched the Cultural Revolution.

Mao's death in 1976 provided the necessary political leeway for renewed reform and readjustment policies. Deng and his supporters expended much effort on cultivating a discourse that unequivocally stressed growth as the sole legitimate measure of progress, a position readily accepted by a population 
weary of years of revolutionary struggle and economic stagnation. This is not to say that Deng altogether rejected the primacy of socialism. However, according to Deng, the socialist character of the economy would prevail as long as public ownership continued to predominate. Despite Deng's assault on the revolutionary left, the economics of the Maoist period continued to cast a long shadow over the era of reform. The traditional questions of the relations between sectors and investment and consumption continued to guide policymaking during the 1980 s and early 1990s. Moreover, although Deng had successfully positioned himself at the apex of Chinese politics, conservative figures such as Li Peng and Chen Yun continued to hold great sway. When reforms proved incompatible with readjustment because they precipitated inflation and pervasive misallocation of capital, conservative influence, and with it the ideological attacks on the "revisionist" program of Deng and his allies, steadily increased.

While, throughout much of the initial period of reform, the conceptual framework and discourse of the Maoist era would thus continue to hold sway, economic and political conditions in the mid- to late 1980 s would put an end to the contention between the reform-minded progressives and the conservatives in favor of readjustment. Neither reform nor readjustment of investment rates in agriculture and industry proved capable of securing the central objective of rapid, but stable growth. While decentralization and marketization resulted in inflation, reintroduction of central planning would invariably cause economic stagnation. The reform program of Chen and Deng was borne out of the tradition of Marxist-Leninist economics, which denied the possibility of inflation within a socialist system. It therefore lacked the conceptual foundations necessary to formulate an appropriate response to the volatility experienced during the immediate post-Mao period of development. Additionally, soes' inefficiency and insatiable demand for capital had caused central debt to rise to unsustainable levels. This prompted a search for novel economic frameworks. Encouraged by the prevailing liberal intellectual climate and increasing openness to the West, economists increasingly turned to market-centric theories. Economists and politicians alike readily adopted monetary theory, which provided detailed explanations of, and prescriptions for, the problem of inflation. Property rights literature too filled an important conceptual gap by providing an explanation for the pervasive problems of capital misallocation and non-productive practices at the firm level.

In this period, several influential economists proposed to extend the scope of reforms in order to put the responsibility of resource allocation squarely on markets and the firms operating within them. However, such discussions were brought to an abrupt end by the political protests of 1989 . The most ardent 
advocates of reform (both economic and political) were removed from their positions of influence. The Tiananmen incident united the remaining leadership in a conviction that the authority of the Party-state in matters both political and economic should remain pervasive and unchallenged. While this did not result in an outright condemnation of Western economic thought, it did convince the leadership that the Party-state ought to remain in firm control of investment and "strategic" sectors of the economy. The resultant paradigm of the socialist market economy, first articulated in 1992 by Jiang Zemin, combined insistence on the incentivizing and disciplinary function of markets and the use of indirect mechanisms of control with a renewed economic authoritarianism. Indeed, within the new "multifarious ownership system" (duozhong suoyouzhi) non-public forms of ownership would predominate. In addition, administrative coordination was largely replaced by market exchange as the chief mechanism of allocation (Lardy 2014). Nevertheless, through the operation of economic levers (jingji gangan) the state was still able to guide the distribution of capital and overall course of development. Indeed, Jiang insisted it was the state's "capacity for control" that would ensure the enduring socialist quality of the economy.

The policies introduced under the banner of market socialism from the early 1990 s onward were effective in curbing economic volatility. Fiscal recentralization eased soft budget constraints within the public sector and curbed rampant discretionary industrial investment by local government. Privatization of loss-making public enterprises and disbandment of the iron rice-bowl system had eased the center's burden. Moreover, public sector restructuring also provided an opportunity to redefine state-market relations, to the effect of realizing a concentration of capital within public industry. The massive layoffs and defunding of social security that accompanied the privatization drive precipitated widespread uncertainty among the labor force, rapidly driving up savings despite extremely low interest rates. This capital was subsequently funneled into centrally controlled industrial conglomerates, establishing a new price scissors that allowed for the rapid expansion of the center's economic clout even as private enterprise continued to ensure strong growth. Thus, it appeared that the mode of economic governance that took shape under the paradigm of the socialist market economy had been successful in bringing about the eagerly anticipated result of strong economic performance under a potent and authoritative state.

The economic and political developments of the 1990s are instrumental to understanding China's incessantly high investment rate. The discontinuation of the factional debate on reform and readjustment and its associated mode of Marxist-Leninist analysis prompted the debate on the respective spheres of 
influence of the state and market and property rights to vanish into the background, not to resurface until 2013. In the combination of market exchange and economic levers, the Party-state had found an agreeable compromise between the demands for efficiency and control. Further reforms were suspended as the state pursued a centralist policy of developing large, scale-efficient stateowned conglomerates while devolving expenditures associated with lossmaking state enterprise to the private sector. Since the implementation of the policy of retaining the large and releasing the small (zhua da fang xiao), little has been done to advance the modern enterprise system, the comprehensive program of public sector restructuring advocated by Zhu Rongji in the early 1990s. Under Jiang, the rapidly expanding private sector was more than able to compensate for the poor performance of soE. Nevertheless, with the transfer of power from Jiang to $\mathrm{Hu}$, and subsequently to $\mathrm{Xi}$, the limitations of industrial growth became ever more apparent.

Academic analyses from the mid-199os onward reflected an increasing concern about the detrimental consequences of investment-driven growth. The scientific development concept promoted by Hu Jintao sought to deal with these challenges through intensified administrative regulation of capital allocation. Through centrally formulated programs that combined lump sum transfers with fiscal and industrial policy, the state sought to divert investment toward rural construction, agriculture and "emerging strategic industries." Unwilling to press on with reforms, the state rather sought to sustain growth through readjustment, that is, by directing investment to relatively underexploited areas of the economy. Thus, even as government sought to deal with worsening socioeconomic inequalities and rampant overaccumulation within heavy industry, it has consistently reverted to measures that rely on the mobilization of capital and build-up of new productive capacity. In consequence, the reciprocal dynamic between elite conceptualizations and economic outcomes that drove the transformation of governance from plan to socialist market has been suspended indefinitely. So has the move away from the entrenched model of investment-driven growth, although some reduction of the excessive investment rate has been seen since Xi Jinping came to power in 2012.

The non-relenting adherence of central government to the principles of state-directed investment, and apparent lack of feasible alternatives, are causes for concern. Although limited progress has been made with reforms along the lines set out by Zhu Rongji, we believe his diagnosis to be correct. Absent the restructuring of property rights, state-market relations and the financial system, there is little reason to expect overinvestment and overcapacity to substantially decrease, or domestic consumption and productivity to increase. However, the window for such comprehensive restructuring is limited. With 
overall growth contracting and government debt sharply on the increase, conditions are already considerably bleaker than they were in 1997, when a proliferating private sector could cushion the destabilizing impact of public sector restructuring. Yet, it is unlikely conditions will improve in the foreseeable future. While central support alone does not guarantee the success of reforms, it is, nevertheless, an indispensable precondition to the resolution of the problems intimately associated with the model of state-directed, investmentdriven growth. It is therefore of concern that the substantial reform program put forward by Xi Jinping and adopted at the meeting of the third plenary session of the Eighteenth Central Committee in November 2013 has stalled, and in some areas even rolled back.

\section{Discourse and Politics}

Although the general dynamic of paradigmatic development and crisis holds well in our analysis of Chinese discourse and governance, we would be remiss in ignoring the influence of politics. Both the substance of China's economic paradigms and the adoption and succession thereof have been shaped and constrained by political conditions. Perhaps most important of these is the CCP's insistence on political hegemony, which is a primary cause for the tenacious adherence to the principles of accumulation-driven growth. For the Chinese population, the legitimacy of the ССP has long rested on the perception that it plays an instrumental role in bringing about economic growth and improving the quality of life for the 1.3 billion Chinese over which it governs. The CCP on its part has precluded the adoption of any solution that would lessen state influence over the economy. Control is exerted primarily through the economic levers put in place from 1993 onward. This intricate system of financial, monetary and industrial policies was introduced with the explicit purpose of guiding investment and delineating private and public spheres of influence within the economy. These governance mechanisms do ensure that the state retains ultimate authority on economic matters, but render it poorly equipped to promote growth strategies that do not rely principally on the expansion of fixed capital. Yet, in the absence of politically acceptable alternatives to the socialist market economy, the Party-state has been forced to respond to China's economic predicaments with policies that accord with its extant techniques of control.

The ideological uniformity that has characterized elite politics from the early 1990s onward stands in stark contrast to the contention between rival factions that defined the preceding period. Not only did scrutiny by political rivals 
condition both sides to continuously adjudicate the efficacy of their proposed programs in the face of current economic developments, but the attendant debate likewise prompted both factions to actively pursue novel concepts and ideas in order to lend new legitimacy to their respective causes. Political competition between rival ideas thus serves an important role in driving the cycle of paradigmatic formulation, establishment and succession, and invigorating discourse. When such competition is curbed-either due to the ideological zeal that characterized the Maoist era or due to the current emphasis on intraparty harmony - the focus on the relationship between concept and actual outcome, as well as the scope for conceptual innovation, suffer.

\section{Merits and Limitations of Discursive Analysis}

Our analysis demonstrated that the consequential changes in the mode of governance cannot be explained on the basis of principles of efficiency or political influence. To be sure, the Chinese case demonstrates that the inherent drive for efficiency which is at the center of the transition and institutional approaches poses but a weak constraint on the modes of economic governance. While highly inefficient forms are unlikely to persist over extended periods of time because they inevitably call into question the legitimacy of dominant paradigms, there is no reason to assume that policy responses to economic imbalances will be instantaneous or necessarily optimal. After all, economic paradigms are ideological constructs; while causal explanations of economic outcomes are central to these paradigms, such explanations may be premised either on empirical evidence or some shared set of values or beliefs. The ideological zeal of the Maoist era allowed suboptimal institutional arrangements to persist-based chiefly on the socialization of consciousness - even in the face of patent evidence of the destructive consequences of a paradigm. No doubt political conditions under Mao were exceptional. Nevertheless, at present political objectives continue to guide and constrain changes of the mode of governance. Thus, in spite of the mounting problems of accumulation-driven growth, the ССP has continued to emphasize its control over investment and sectoral development.

Likewise, our analysis shows that the programs and policies that shaped governance throughout the different stages of economic development were more comprehensive and coherent than could be expected if they had been mere outcomes of political bargaining by different interest groups. Nor can they simply be reduced to expropriatory motives or attempts by rival factions to increase their political stature. Perspectives that present changes in 
governance solely as an outcome of politicking between groups with diverging interests would be hard-pressed to explain why the leadership acquiesced with the introduction of reforms and readjustments, even though it would inevitably lead to the attrition of central influence. Rather, such initiatives have to be understood as concerted efforts by political actors to formulate encompassing responses to extant economic problems.

These conclusions about the pursuit of efficiency and interest present a paradox: rational decision-making is constrained by political influence, yet policies do not unambiguously represent political interest. In resolving this apparent contradiction, we turn to discourse. In contrast to the sterile models of actorhood provided by the efficiency and political approach, discourse analysis holds that sensemaking and politicking occur in tandem. The economic paradigms developed by central leadership comprise both the perceived cause and effect relationships within the economic system and the general objectives of economic activity. As such, they provide at once the cognitive and normative underpinnings for policymaking. In certain instances, political positions will take shape alongside competing interpretations of economic phenomena (as was the case with the reform and readjustment factions) or political interests will delineate the set of legitimate representations of, and responses to, emerging economic problems (explaining the state's current approach to the issues of socioeconomic disparity and the transformation of the mode of development). However, more often than not, the processes of sensemaking and politicking will interlace in an organic manner, as ideological convictions shape the manner in which we seek to understand and interact with our social and material environments.

Notwithstanding the merits of the discursive approach in explaining policymaking, we ought not to ignore the interdependencies between discourse, economics and politics. As repeatedly demonstrated in our analysis, elite conceptualizations of the economic system cannot prefigure the dynamics that end up driving economic growth, much less forestall the grave imbalances that periodically emerged. The local experimentation emphasized by more recent versions of fragmented authoritarianism plays an important role in explaining this growth and imbalance. The momentous upturn of economic activity within the rural sector in the late 1970s and 1980 s was due in large part to an unanticipated reciprocity between fiscal decentralization and marketization. When local government was granted the right to claim taxes on newly established TVEs, their establishment became a major focus of local policy. Likewise, the pervasive privatization that occurred under the guise of "releasing the small" in the late 1990s was driven by local governments eager to supplement their dwindling revenues through the sale of soE. Thus, while the general char- 
acter of state engagement with the economy is determined by national policies, the center cannot often anticipate the manner in which local bureaucracy will utilize its authority.

Due consideration needs to be given to the institutional interdependencies that are the focus of efficiency-based approaches too. Many of the destabilizing dynamics that gave cause for the readjustment of the economic paradigms were due to antagonisms between institutional arrangements within the spheres of capital, labor, and the organization of production and exchange. In the early stages of reform, market relations were introduced while the traditional distribution of financial responsibilities within the public sector remained unchanged. The resulting soft budget constraint prompted an insatiable demand for credit among SOE, resulting in inflationary crises throughout the 1980 s and 1990s. While recentralization of the fiscal system and banking restored macroeconomic stability, it likewise precipitated increasing disparity between the private and public economy and rural and urban sectors, undermining social stability. Such imbalances may arise when institutional change proceeds in an asynchronous or partial manner, causing antagonisms between different spheres of governance even as existing ones are resolved.

In sum, we argue that a holistic understanding of the development of the Chinese economy and its associated modes of governance requires in-depth analysis of the elite conceptualizations that describe the objectives and mechanisms of state influence, the manner in which these paradigms are adopted and adapted by the various political and bureaucratic constituents at the central and local level, and the way in which economic institutions interact to create (un)anticipated synergies and imbalances.

\section{Dynamics of Discourse: Insights from the Chinese Case}

Although our chief interest has been to describe and analyze China's economic paradigms and their relation to economic governance, our study provides insights into the discursive process too. Here we briefly discuss these insights. We found the general model of economic paradigms to provide a strong fit with the pattern of change of Chinese discourse and governance. The remarkable trajectory of growth over more than six decades of development under CCP rule have been accompanied by destabilizing forces that have necessitated comprehensive periodic adjustments to the state's conceptualization of the economic process and its mode of economic governance. There are, however, several caveats. The first of these relates to the functionalism implicit in the process of paradigmatic succession. No guarantee exists that paradigmatic 
crisis will prompt the articulation and adoption of a conceptual solution. Entrenched political positions or interests can prevent alternative paradigms from gaining legitimacy, as was the case with the program of reform and readjustment throughout the era of Mao. Even when political factors do not entirely prohibit the introduction of novel conceptualizations of the economic system, they may well impose constraints and conditions that preclude the articulation of feasible alternatives. Certainly, the impasse of economic governance under the regimes of $\mathrm{Hu}$ and $\mathrm{Xi}$ is due, to large extent, to the continued insistence on extensive state control over investment and industry, which severely limits the set of possible responses to the problems of dwindling returns in industry and a lack of domestic consumption. The dynamic of crisis, reconceptualization and adoption thus does not necessarily proceed uninterruptedly, but may be marked by extended periods of conceptual stagnation.

Qualifications apply also to the locus of change. Although Chinese economic discourse and governance have been characterized by periodic bouts of comprehensive transformation, allowing us to identify three distinct periods, such change has not unfolded synchronically at all levels of conceptualization. As Hall (1993) implies, paradigms are multilevel constructs, comprising ideological and ontological, epistemological and technical dimensions. They delineate the elements (whether abstract or concrete) and relationships between them which constitute the economic system, and from there develop propositional knowledge (specific causal mechanisms) and techniques for manipulating these causal mechanisms in order to achieve some desired result. Rarely does a shift in paradigms signify the simultaneous transformation of all these levels. Often, changes on one level are conditional on changes in others. Under Deng, the delegitimization of Mao's dialectics was a precondition to the substitution of continuous revolutionary struggle with the program of reform and readjustment. After all, the contention between Party and state leaders in the central planning era had not revolved around whether or not sectoral imbalances existed, but rather their significance within the greater economic system. According to Mao, contradiction was a fact of life, which could be overcome through continuous revolution. Only when Deng replaced the socialization of consciousness with pragmatism as the guiding principle, and established the ratio of public ownership as the essence of socialism, could the reforms within agriculture and adjustments to the investment rate proceed.

In other cases, changes may be partial, which may result in disjunctions between the different levels of the economic paradigm. After Jiang, through his third liberation of thought, reduced the quality of socialism to a measure of the state's capacity for economic control, the debate on the ideological foundations of the economic paradigm all but ceased and economic discussions 
came to revolve instead around the technical matters of macroeconomic stability and microeconomic efficiency. Consequently, while economic discourse under $\mathrm{Hu}$ saw the development of novel propositions about the causes of the mounting imbalances within the economy, these did not prompt a reevaluation of entrenched (but largely concealed) ontological and ideological assumptions about the role of the state. Because of the maintenance of the ideological status quo, Hu's scientific development concept continued to propagate entrenched centralist measures that sought to promote growth through state-guided investments, despite mounting evidence of the inefficacy of stateguided, investment-driven responses to economic disparity and the dearth of domestic consumption.

Finally, the evolution of economic paradigms is affected by the processes of sensemaking and politicking. In its simplest form, change is effectuated through a process whereby extant propositions are scrutinized against observed phenomena. In the late 1950s, the discrepancy between predicted and actual outcomes of the strategy of accelerated accumulation led to the formulation of reform and readjustment. While this program entailed a consequential reevaluation of the roles of the law of value and accelerated versus balanced proportionate development, the economic categories and relationships which formed the basis of the paradigm remained unchanged. Alternatively, when extant concepts fail to account for observed phenomena, sensemaking and politicking may entail the introduction of novel frameworks. The unprecedented problem of inflation and systemic overaccumulation motivated the introduction of monetary and property rights theory, which in turn gave occasion for the articulation of the socialist market economy. However, the establishment of novel economic paradigms requires not only cognitive but normative change too. Neither the program of reform and readjustment, nor the socialist market economy, could attain legitimacy under prevailing ideological conditions. This prompted both Deng and Jiang to engage in a redefinition of socialism and its relation to the economic system. Subtler still, but not less consequential, was the process whereby ontological and ideological principles were concealed from discourse. Due to the implicit negation of the superstructure (the sociopolitical alignment in which the relations of production are embedded), effectuated by Jiang's third liberalization of thought, elite discourse no longer provided recourse for critical appraisal of the legitimate role of the state within the economic system. ${ }^{258}$ In this way, the absence of

$25^{8}$ Marxist-Leninist theory is still a compulsory element of the education of cadres within the CCP. However, these theories have little to no bearing on either the elite discourse that shapes economic governance or the academic debate that informs it. 
discussion of the nature of the economic system has enabled the propagation of a centralist mode of governance even in the face of increasing contradiction.

On the basis of the foregoing, we suggest that attention to the sequence, locus, and cognitive and political dimensions of change could enhance our understanding of why and how economic paradigms evolve. It is worthwhile asking, however, to what extent some of our observations are attributable to the particular nature of Chinese politics. The dearth of competing conceptions within economic discourse are largely due to the absence of political rivals. While intra-Party factionalism provided an alternative drive for discursive contention during the regimes of Mao and Deng, post-Tiananmen politics have been characterized more by internal struggles for political power rather than rivalry between templates for economic organization. The CCP's political monopoly may likewise attenuate the evolutionary pressure exerted by economic imbalances. Whereas in pluralistic systems, non-ruling parties are quick to seize on economic predicaments to call into question the efficacy and legitimacy of incumbent government, in China such external political pressure is absent. The torpor of the general dynamic of paradigmatic change can thus hardly be explained without taking into account China's political institutions. However, even if they do not exist to the same degree as in China, obstacles to political contention are pervasive in multiparty systems too. Therefore, we believe our insights into the discursive process to have merit beyond the Chinese case.

\section{Conclusion}

The literature on Chinese economic development is expansive and, considering China's ongoing growth and its increasing stature within the global economy, is surely set to continue to develop rapidly in years to come. While there is no shortage of policy studies or historical narratives, we have sought to complement the literature with an analysis of the development of China's economic discourse and governance from the establishment of the People's Republic onward. The emphasis on economic paradigms illuminated aspects of the character and dynamics of economic governance and development that cannot be adequately captured by perspectives that only stress the pressure for institutional efficiency or competition for influence by central and local political actors. It likewise allows us to understand why certain ideas continue to shape governance even as they appear to contradict the economic diagnoses of China's economic leadership. 
Such an approach focusing on economic discourse and development paradigms - or ideational factors in Sarah Eaton's parlance-needs to take into consideration that Chinese economic plans and decisions are framed within the context of Marxist concepts and terms, although Western neoliberal ideas from the 199os have increasingly influenced the economic policy debate. In a more general sense, our analysis suggests that studies of economic governance ought to be informed by both contextual knowledge and general dynamics. The study of discourse captures both the particular, path-dependent development of ideas, and the generic processes of sensemaking and politicking that drive the change of economic development.

Arguably the most salient proof for the persistence of the template of capital-intensive, industry-centric growth has been the failure to realize the original objective of readjustment, formulated some five decades ago. Despite leaderships' insistence on the importance of increasing the rate of consumption and promoting the development of agriculture, the rate of GFCF has continued to rise, and all the while agriculture's share of GDP has been declining. Although reforms were initially regarded as a necessary expedient for readjustment, the reorganization of the financial regime and industrial relations has rather proved instrumental in sustaining the expansion of industrial capacity. After more than a decade of Keynesian central policy and limited institutional change, increasing socioeconomic inequality and slowing growth seem to espouse a growing conviction among economic leadership and economists alike that comprehensive expansion of market exchange and private property rights — of the sort discussed during the fourteenth Party congress of 1994are necessary to sustain economic development.

This conviction was the driving motivation behind the formulation of the comprehensive reform program adopted by the third plenum of the Central Committee in November 2013. That most of the proposals have not yet been realized is, once again, a reflection of the fact that economic debate and policy implementation often do not follow in tandem. It also reflects the power of centralizing forces embedded in a polity which continues to be dominated by a Leninist Party organization.

This study also shows that although the СCP has maintained a strong unitary power over Chinese society and has exercised a dominating and hegemonic influence on economic policymaking, in general a lively debate has taken place in Chinese scholarly journals and in print media on the goals and directions of economic development. To be true during the Great Leap Forward and the Cultural Revolution public debate on economic issues subsided and instead revolutionary slogans took over. But in the early 1960s and again after the 
implementation of economic reforms and open-door policies in early 1979, economic policymaking was embedded in a framework of contending ideas and suggestions on economic reform and development. In order to understand how China's continued search for economic growth and modernization may unfold, it is essential to carefully study the Chinese discourse and identify the various views on how to combine economic modernization and reform with continued growth in the context of a centralized political order. 